7-1997

\title{
Failure Case Studies and Ethics in Engineering Mechanics Courses
}

Norbert J. Delatte

Cleveland State University, n.delatte@csuohio.edu

Follow this and additional works at: https://engagedscholarship.csuohio.edu/encee_facpub

Part of the Civil Engineering Commons, and the Engineering Education Commons

How does access to this work benefit you? Let us know!

Publisher's Statement

(CASCE

\section{Original Citation}

Delatte, N.J. (1997). "Failure Case Studies and Ethics in Engineering Mechanics Courses." J.Prof.Issues Eng.Educ.Pract., 123(3), 111-116.

This Article is brought to you for free and open access by the Civil and Environmental Engineering at EngagedScholarship@CSU. It has been accepted for inclusion in Civil and Environmental Engineering Faculty Publications by an authorized administrator of EngagedScholarship@CSU. For more information, please contact library.es@csuohio.edu. 


\title{
Failure Case Studies and Ethics in Engineering Mechanics Courses
}

\author{
By Norbert J. Delatte Jr., ${ }^{1}$ Member, ASCE
}

\begin{abstract}
Often, engineering students do not study engineering failures or discuss ethics until they take upper division undergraduate courses or graduate level courses. One drawback to this approach is that problems analyzed in introductory courses are often contrived, uninteresting, and bear little relation to the problems encountered in engineering practice. At the point when educators need to grab the student's interest in engineering most, they should show the excitement and relevance of the profession. Another is that the students encounter the issues of ethics, responsibility, and accountability that are often highlighted by a failure, late in their engineering education. As a result, they may see these issues as secondary to engineering practice rather than fundamentally embedded. Examples of failure case studies and their incorporation into introductory engineering mechanics courses are discussed, along with ethical implications. When possible, problems should be selected so that the students can perform the calculations. By incorporating this material earlier in engineering education, it is possible to forge a stronger link between engineering education and practice.
\end{abstract}

\section{INTRODUCTION}

The study of engineering failures can offer students valuable insights into structural behavior and the responsibilities of the engineering profession. Occasionally, forensic engineering courses are offered at the graduate level. Since it is not practical to introduce yet another course into already crowded undergraduate engineering curricula, the suggestion has been made to incorporate failure case studies into other courses (Rendon-Herrero 1993). Unfortunately, engineering students rarely encounter failure case studies before taking upper division undergraduate or graduate level courses. Instead, in introductory engineering mechanics courses, such as statics, dynamics, and mechanics of materials, they often study contrived, simple problems with limited practical application. This is unfortunate because the opportunity to inspire students with the excitement and relevance of the profession is missed.

In many cases, the relevant principles of engineering science may be brought out in the study of failure case studies. The case studies may be used as example problems in lectures, or as homework problems. The problems may have to be simplified so the students can perform the calculations. The issues of responsibility, accountability, or ethics that led to or influenced the failure should also be addressed by the instructor. When possible, educators should bring practitioners who have investigated failures into the classroom as guest lecturers.

\section{SUGGESTED FORMAT}

A format for incorporating a failure case study into a lesson is suggested in the following:

1. Learning point: The case study must be tied to a specific course topic. Possible learning points include drawing a correct and complete free-body diagram, calculating forces due to impacts, stress-strain relationships, the effect of structural deformation on performance, or buckling.

2. Narrative: The events leading to the failure should be summarized. The problem description may be brief but should include all likely causes of the failure. If the case study is assigned as a homework problem, references may be provided or recommended, or left to the student. Ideally, if failure case studies can be integrated into several courses in the curriculum, a supplemental text such as Why Buildings Fall Down (Levy and Salvadori 1992), Design and Construction Failures (Kaminetzky 1991), or Construction Failure (Feld and Carper 1997) could be purchased by students and used in multiple courses.

3. Technical aspects and calculations: The problem model may be simplified so that the students can perform the calculations. The lesson will probably be more effective if the students can "discover" the reason for the collapse through their calculations. In some cases the case study can be presented without calculations; however, when possible they should be incorporated.

4. Ethical considerations: In each case the ethical implications of the case study should be considered. Did the engineer or engineers concerned do all that could be reasonably expected to prevent the problem? Were there any relevant legal findings? Judges, lawyers, juries, and other engineers may have different interpretations of what may reasonably be foreseen by a designer. What can students learn from these case studies that will better prepare them to become practitioners of the engineering profession?

\section{EXAMPLE CASE STUDIES}

Sample case studies for topics in statics, dynamics, and mechanics of materials are discussed in the following.

\section{Statics: Free-Body Diagram}

\section{Hyatt Regency Walkway Collapse}

Learning Point. The free-body diagram is the basic equilibrium analysis tool to determine the forces that structures must support. It is the starting point for any structural analysis.

Narrative. On July 17, 1981, a pair of walkways in the Hyatt Regency Hotel in Kansas City, Kans., collapsed, killing 114 people and injuring over 200 . Two walkways were stacked on top of each other and suspended from the ceiling; the top walkway fell on the bottom walkway, and the two fell onto the floor of the crowded atrium. The relevant facts of the case were

1. The hanger detail for the two walkways, as originally designed, could not be built. The steel fabricator requested a change in the detail, and the engineer of record approved it without checking the calculations. 
2. Examination of the box beams supporting the upper walkway after the collapse showed that the upper hanger rod had pulled through the beam. The beam was made of two steel channels welded together (Levy and Salvadori 1992; Kaminetzky 1991; Rubin and Banick 1987; Feld and Carper 1997). The instructor may have to explain the structural behavior of these details.

3. Although many people were on the walkway when it collapsed, the actual load was still much less than the code mandated capacity for the system (Levy and Salvadori 1992).

Technical Aspects and Calculations. Provide the original design and as-built box beam hanger details (Fig. 1). By drawing free-body diagrams of the two details, it can be shown that the load transferred by the nut on the hanger rod to the bottom
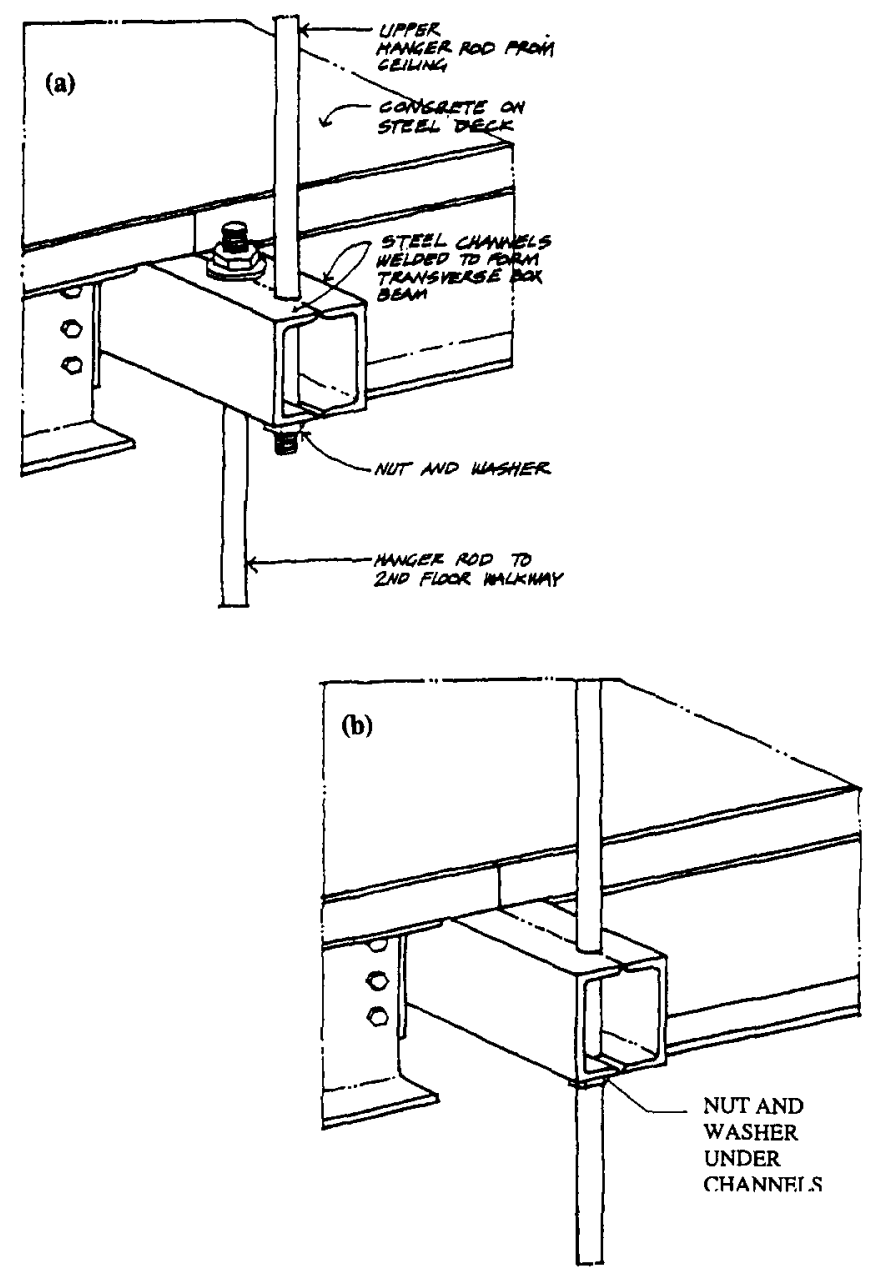

FIG. 1. Hyatt Regency Hanger Details As-Built (a)z and As-Designed (b) (Levy and Salvadori 1992) (Reprinted by Permission)

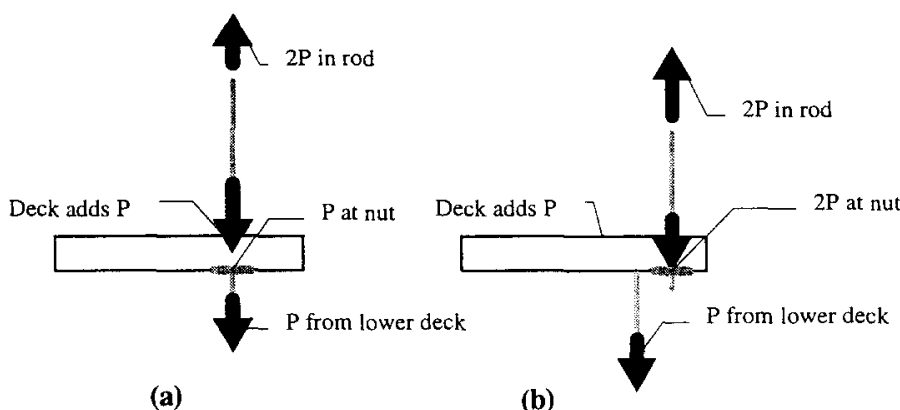

(a)

(b)

FIG. 2. Free-Body Diagrams: (a) As-Designed Details; (b) AsBuilt Details (Reprinted by Permission)

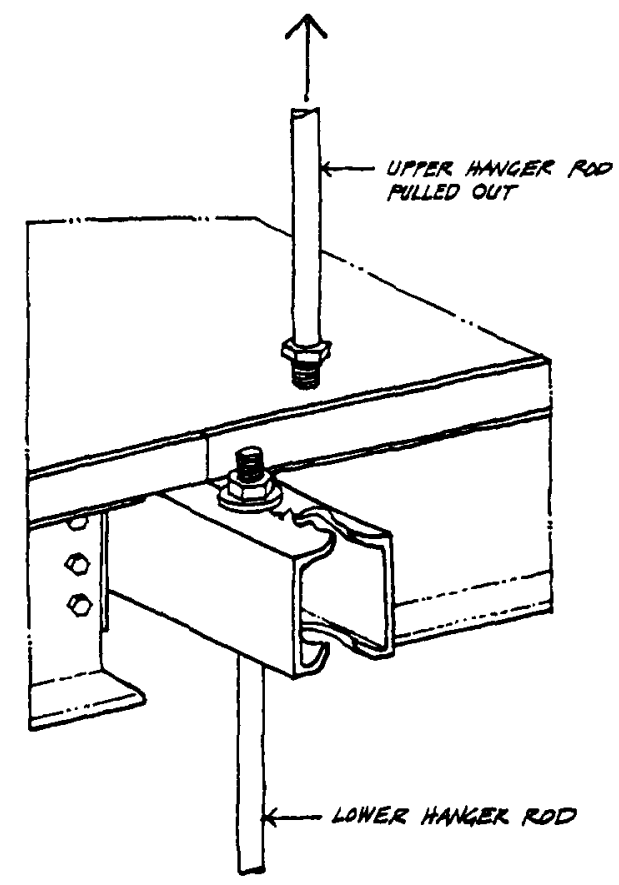

FIG. 3. Pulled-Out Rod at Fourth-Floor Box Beam (Levy and Salvadori 1992) (Reprinted by Permission)

of the box beam was doubled in the as-built detail (Fig. 2). The beam design was also unsatisfactory, and this condition was aggravated by the increased load on the nut. The nut pulled through the box beam (Fig. 3).

Ethical Considerations. According to Rubin and Banick (1987), the engineers were contacted repeatedly during fabrication and construction by individuals with doubts about the adequacy of the detail, and claimed more than once to have checked it. Prudent engineers will view a question about the safety of their design as an opportunity to review the work and reassure the public, rather than as an attack on their expertise. Ethical issues are thoroughly discussed in Feld and Carper (1997).

\section{T.W. Love Dam Cantilever Form Failure}

Learning Point. It is important to show all support reactions on a free-body diagram. If support reactions are omitted, the model of structural behavior may be oversimplified or dangerously incorrect.

Narrative. In 1981 concrete formwork at a dam construction site failed, killing two workers and injuring 13 . The formwork was anchored into previously placed concrete, and the anchors were intended to be loaded in tension only (Kaminetzky 1991).

Technical Aspects and Calculations. Fig. 4 shows the formwork as placed on the sloping concrete, with the assumed forces in the anchor bolts (shown as "she bolt"). However, with this structural model there is no equilibrating shear force in the bolts to keep the formwork from sliding down the face of the dam (Fig. 5). This required shear force induced a bending moment in the anchor bolt. Examination of the failed anchor bolts indicated bending fracture (Kaminetzky 1991).

Ethical Considerations. The formwork was designed by a formwork vendor (Kaminetzky 1991). Formwork is often left to the contractor, but formwork failures can lead to substantial loss of life and property. Who should take responsibility for formwork on a job site? 


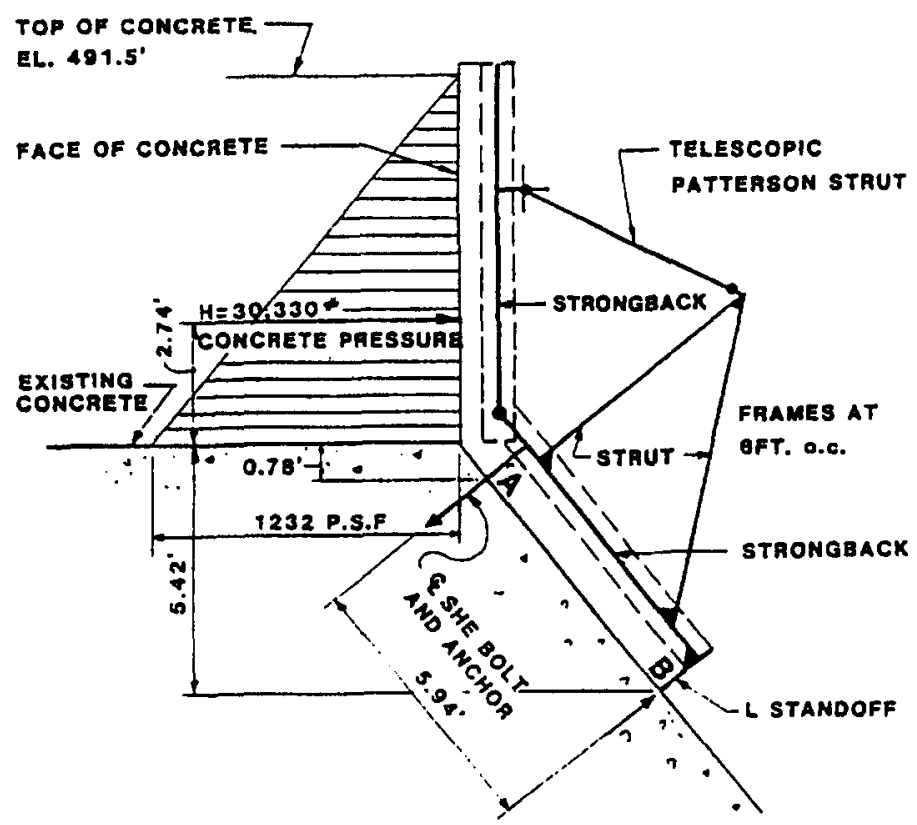

FIG. 4. T. W. Love Dam Formwork, System Not in Equilibrium (Kaminetzky 1991) (Reprinted by Permission)

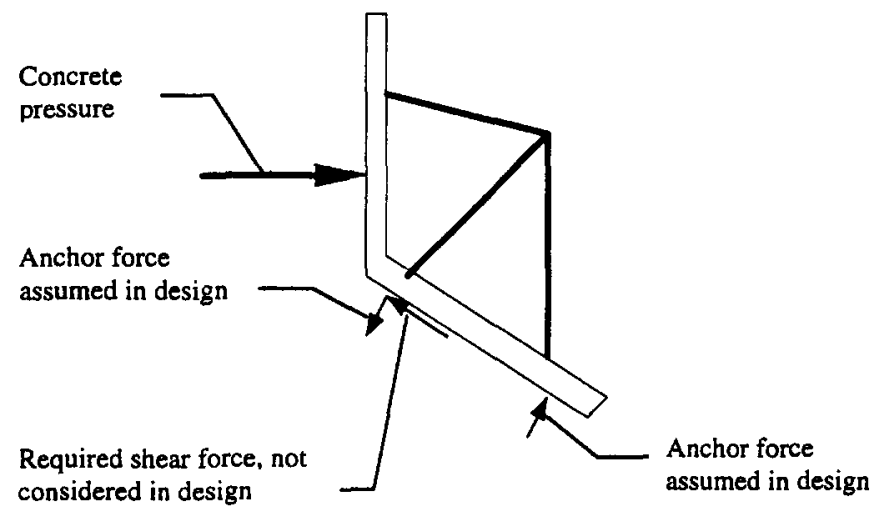

FIG. 5. T. W. Love Dam Formwork Support Reactions (Reprinted by Permission)

\section{Dynamics}

\section{Mass Moment of Inertia and Stiffness: Tacoma Narrows} Bridge Collapse

Learning Point. The mass moment of inertia of a structural member is a measure of its resistance to twisting forces and accelerations.

Narrative. Only three months after the Tacoma Narrows bridge opened in 1940, tie-down cables intended to stiffen the bridge snapped during a windstorm. The cables had been anchored into the ground and attached to the parts of the bridge deck that were moving the most. The cables were replaced. The bridge became notorious for large movements during high winds. On November 7, 1940, with a wind velocity of about $60 \mathrm{k} / \mathrm{h}$, the bridge began twisting and oscillating violently. The bridge was twisting about $45^{\circ}$ in two waves, and oscillating up and down $1 \mathrm{~m}$ in nine waves. The oscillations reached 8 $\mathrm{m}$ as the bridge tore itself apart (Levy and Salvadori 1992; Feld and Carper; 1997). The dramatic failure of the bridge is shown in Fig. 6.

Technical Aspects and Calculations. The mathematics involved in the oscillations of a slender bridge are difficult and were not well understood in 1940. However, suspension bridges had failed in the 18th and 19th centuries. The Tacoma Narrows bridge was three times more flexible than the Golden

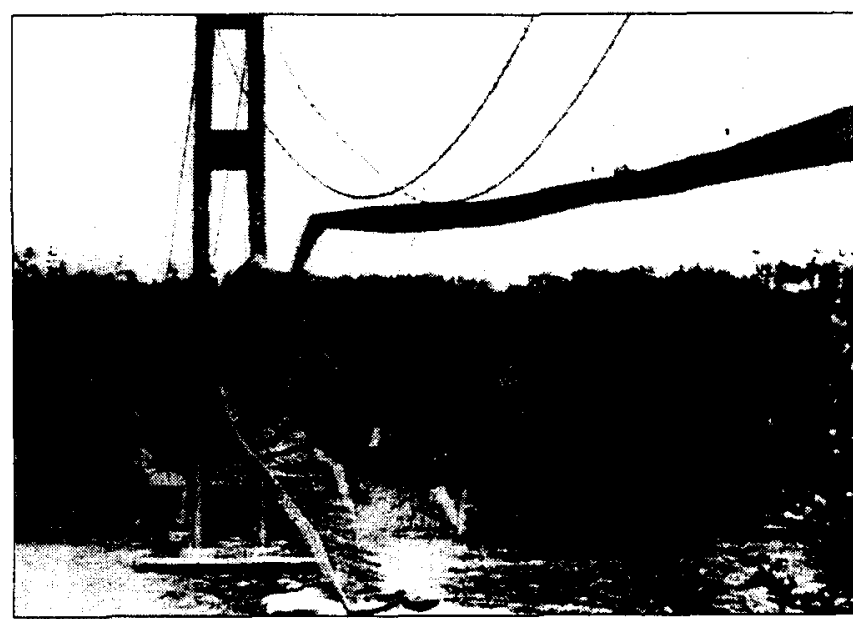

FIG. 6. Failure of Tacoma Narrows Bridge (Feld and Carper 1997) (Reprinted by Permission)

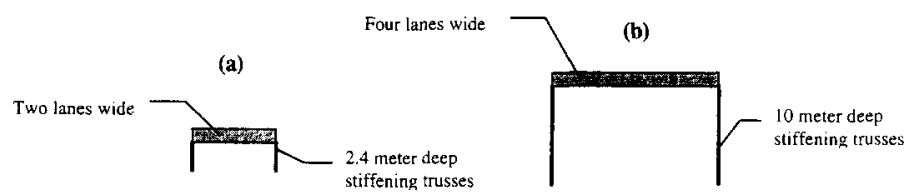

FIG. 7. Deck Cross Sections (Not to Scale): (a) Original; (b) Replacement

Gate or George Washington bridges. Like the Bronx-Whitestone Bridge, it used a damper, but the damper failed almost immediately. The other bridges had a much greater stiffness and mass moment of inertia, and were less prone to windinduced accelerations (Levy and Salvadori 1992). The replacement bridge, which is still in use, had four lanes rather than two and $10-\mathrm{m}$ deep stiffening trusses in place of the original 2.4-m trusses (Feld and Carper 1997). The resistance to the vertical oscillation is proportional to the mass of the bridge, which is doubled in the replacement design. The resistance to rotational acceleration is represented by the mass moment of inertia $I$

$$
I=\int_{m} r^{2} d m
$$

where: $m=$ mass; and $r=$ moment arm from an axis to the element $d m$ (Hibbeler 1995).

Thus, the doubling of the mass of the deck plus the much greater depth of the stiffening trusses considerably increased the mass moment of inertia of the replacement bridge compared to the original. Doubling the number of lanes alone increases the mass by a factor of 2 , the moment arm by a factor of 2 , and the mass moment of inertia by a factor of 8 . The original and replacement decks are shown in Fig. 7.

Ethical Considerations. Should more attention have been paid to the causes of the tie-down cable failure? Is the occasional failure of a ground-breaking structure part of the cost of doing business? Should we differentiate between failures caused by neglect (the Hyatt Regency) and failures caused by ignorance in pushing the state of the art?

\section{Kinetics: Bomber Crashes into Empire State Building}

Learning Point. There are several ways to calculate forces due to impacts. Although rare, large vehicle impacts into buildings are possible.

Narrative. On July 28, 1945, a 10-t (10,000-kg) B-25 bomber crashed into the Empire State Building at an estimated $400 \mathrm{k} / \mathrm{h}$ into the north face of the 79th floor. Although several 


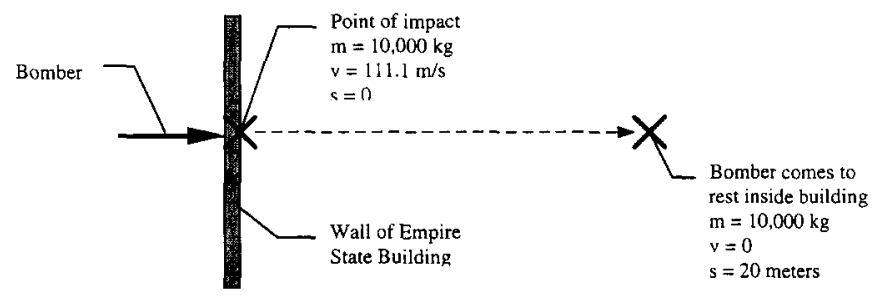

FIG. 8. B-25 Bomber Crashes into the Empire State Bullding

people were killed, the building remained standing (Levy and Salvadori 1992).

Technical Aspects and Calculations. To estimate the force applied to the building, we must estimate either the deceleration of the bomber as it crashed into the building (and use the force-acceleration method), estimate the distance it took the bomber to come to rest (and use work-energy), or estimate the time it took the bomber to come to rest (and use impulse-momentum). The bomber did not pass through the building, so a distance of $10-20 \mathrm{~m}$ for the plane to come to rest could be used for calculations. If the bomber came to rest in $20 \mathrm{~m}$ with a constant deceleration, the force would be about $4,440 \mathrm{kN}$ exerted over about $0.25 \mathrm{~s}$ (Fig. 8).

All three of these methods are derived from $F=m a$ (Hibbeler 1995). The acceleration is assumed to be constant and is integrated once for velocity and twice for distance traveled. With an initial velocity of $400 \mathrm{k} / \mathrm{h}$ or $111.1 \mathrm{~m} / \mathrm{s}$, a final velocity of zero, and an initial position of zero and a final position of $20 \mathrm{~m}$, the velocity equation becomes

$$
v(t)=a t+111.1
$$

and the position equation becomes

$$
s(t)=\frac{a t^{2}}{2}+111.1 t
$$

Solving these two equations simultaneously gives a $t$ of about $0.36 \mathrm{~s}$ and an acceleration of $308.6 \mathrm{~m} / \mathrm{s}^{2}$ (actually a deceleration, which will affect the direction of the force).

- Force acceleration: From $F=m a$

$$
F=10,000 \mathrm{~kg} \times 308.6 \mathrm{~m} / \mathrm{s}^{2}=3,086 \mathrm{kN}
$$

- Work energy: Initial kinetic energy plus work done equals final kinetic energy leads to

$$
T_{1}+\sum U_{1-2}=T_{2}
$$

where $T_{1}=$ initial kinetic energy; $U_{1-2}=$ work done between position 1 and position 2 (initial and final); and $T_{2}$ = final kinetic energy. Initial kinetic energy is

$$
T_{1}=\frac{1}{2} m v^{2}
$$

where $m=$ mass $(10,000 \mathrm{~kg}$, given previously); and $v=$ initial velocity of $111.1 \mathrm{~m} / \mathrm{s}$. Thus, the initial kinetic energy is $61,700,000 \mathrm{~N} \cdot \mathrm{m}$

$$
U_{1-2}=F \times d
$$

where $F=$ unknown force; and $d=$ distance of $20 \mathrm{~m}$. The final kinetic energy is zero because the final velocity is zero, after the bomber comes to rest. Finally, to get the force

$$
F=\frac{U_{1-2}}{d}=\frac{61,700,000}{20}=3,086 \mathrm{kN}
$$

which is exactly the same result as before.
- Impulse-momentum: The initial momentum plus the impulse equals the final momentum, or

$$
m_{1} v_{1}+\int_{t_{1}}^{t_{2}} F d t=m_{2} v_{2}
$$

For a constant force, this becomes

$$
m_{1} v_{1}+F\left(t_{2}-t_{1}\right)=m_{2} v_{2}
$$

Substituting previous values of $10,000 \mathrm{~kg}$ for $m_{1}$ and $m_{2}$, $111.1 \mathrm{~m} / \mathrm{s}$ for $v_{1}$, zero for $v_{2}$, and $0.36 \mathrm{~s}$ for the time elapsed $\left(t_{2}-t_{1}\right)$, we once more calculate

$$
F=\frac{m_{1} v_{1}}{\left(t_{2}-t_{1}\right)}=\frac{10,000 \times 111.1}{0.36}=3,086 \mathrm{kN}
$$

This problem is useful for demonstrating the equivalence of the three methods.

Ethical Considerations. A bomber crashing into a building is an extremely unlikely occurrence. However, the consequences of the collapse of a large building are very grave. How should the profession guard against rare, but severe events? In a large and complicated project, is there an obligation to go beyond building code requirements? For example, for nuclear reactor containment vessels, what extreme events should engineers consider? What about buildings subject to terrorist attacks?

\section{Mechanics of Materials}

Stress and Strain: Shrinkage of Concrete Masonry Units and Swelling of Brick Masonry

Learning Point. Even in the absence of applied loading, changes in moisture and temperature in materials will cause strain. If the strain is resisted, stresses occur. The stresses can cause failure of building elements.

Narrative. Concrete frames and concrete masonry units shrink with time. Clay bricks, on the other hand, expand with time. Two buildings in Alberta, Canada, constructed of concrete masonry units (CMUs) showed patterns of shrinkageinduced cracks about $2 \mathrm{~m}$ apart (Mattar and Morstead 1987). Buildings with brick cladding, in contrast, often experience compressive stress buildup from restrained expansion (Beasley 1987).

Technical Aspects and Calculations. According to Drysdale et al. (1994), clay bricks have thermal coefficients of expansion of $4.5-7.2 \times 10^{-6} \mathrm{~mm} / \mathrm{mm} /{ }^{\circ} \mathrm{C}$ and moisture expansion of $0.016-0.028 \%$ at approximately $500 \mathrm{~d}$ (for Canadian bricks). For CMU the thermal coefficient was $7.2-9.0 \times 10^{-6}$ $\mathrm{mm} / \mathrm{mm} /{ }^{\circ} \mathrm{C}$, and shrinkage was $0.01-0.06 \%$ (ultimate shrinkage values). The modulus of elasticity $(E)$ for masonry is correlated with strength; the modulus for clay bricks with a compressive strength of $35 \mathrm{MPa}$ may be $10-28 \mathrm{GPa}$, and the modulus for CMU with a $17-\mathrm{MPa}$ compressive strength may be from 7.6 to $10 \mathrm{GPa}$.

If we take typical values for a 30-m brick wall, $500 \mathrm{~d}$ after construction, we can calculate a strain due to moisture expansion $(0.02 \%)$ and a $28^{\circ} \mathrm{C}$ temperature rise (thermal coefficient $6.3 \times 10^{-6} \mathrm{~mm} / \mathrm{mm} /{ }^{\circ} \mathrm{C}$ ) of $0.0375 \%$. Multiplying this by a modulus of elasticity of $20.7 \mathrm{GPa}$, the compressive stress is $7.75 \mathrm{MPa}$ if the expansion is restrained. This is not enough to fail a single unit but may be enough to buckle a wall. If the wall is allowed to move, it will move $11.4 \mathrm{~mm}$. Therefore, the designer must provide a gap of at least this much if stress buildup is to be prevented.

For CMU with $0.04 \%$ shrinkage and a $28^{\circ} \mathrm{C}$ temperature drop (thermal coefficient $8.1 \times 10^{-6} \mathrm{~mm} / \mathrm{mm} /{ }^{\circ} \mathrm{C}$ ), the strain 
would be $0.0625 \%$. If the wall is restrained, the tensile stress (for $E=13.8 \mathrm{GPa}$ ) would be $8.6-\mathrm{MPa}$ tension, which is enough to crack the block. To prevent cracking, control joints are required.

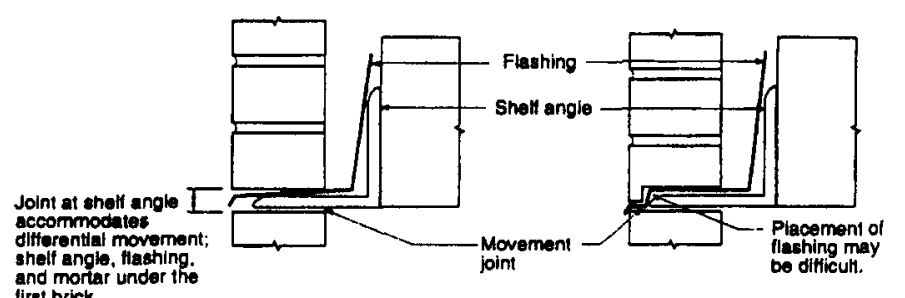

(a)

(b)

FIG. 9. Masonry Detall Allowing Movement (Drysdale ot al. 1994): (a) Requirement for Thicker Mortar Joints; (b) Use of Notched Brick to Maintain Standard Mortar Joint Thickness (Reprinted by Permission)
Problems are exacerbated when brick facades are tied to concrete or CMU structures without proper detailing to allow for movement. A typical detail allowing expansion of a brick facade and preventing stress buildup is shown in Fig. 9.

Ethical Considerations. Who is responsible for structural problems caused by poor detailing of masonry? Note that these problems often show up years after the facility is put into service. Many engineers are not aware of the existence or magnitude of these movements, which may be dangerous if ignored.

Structural Deformation as Warning of Impending Collapse: Hartford Civic Center Arena

Learning Point. Higher than expected deformations may indicate that the structure is overloaded.

Narrative. At approximately 4:15 a.m. on January 17, 1978, the roof of the Hartford Civic Center Arena collapsed.

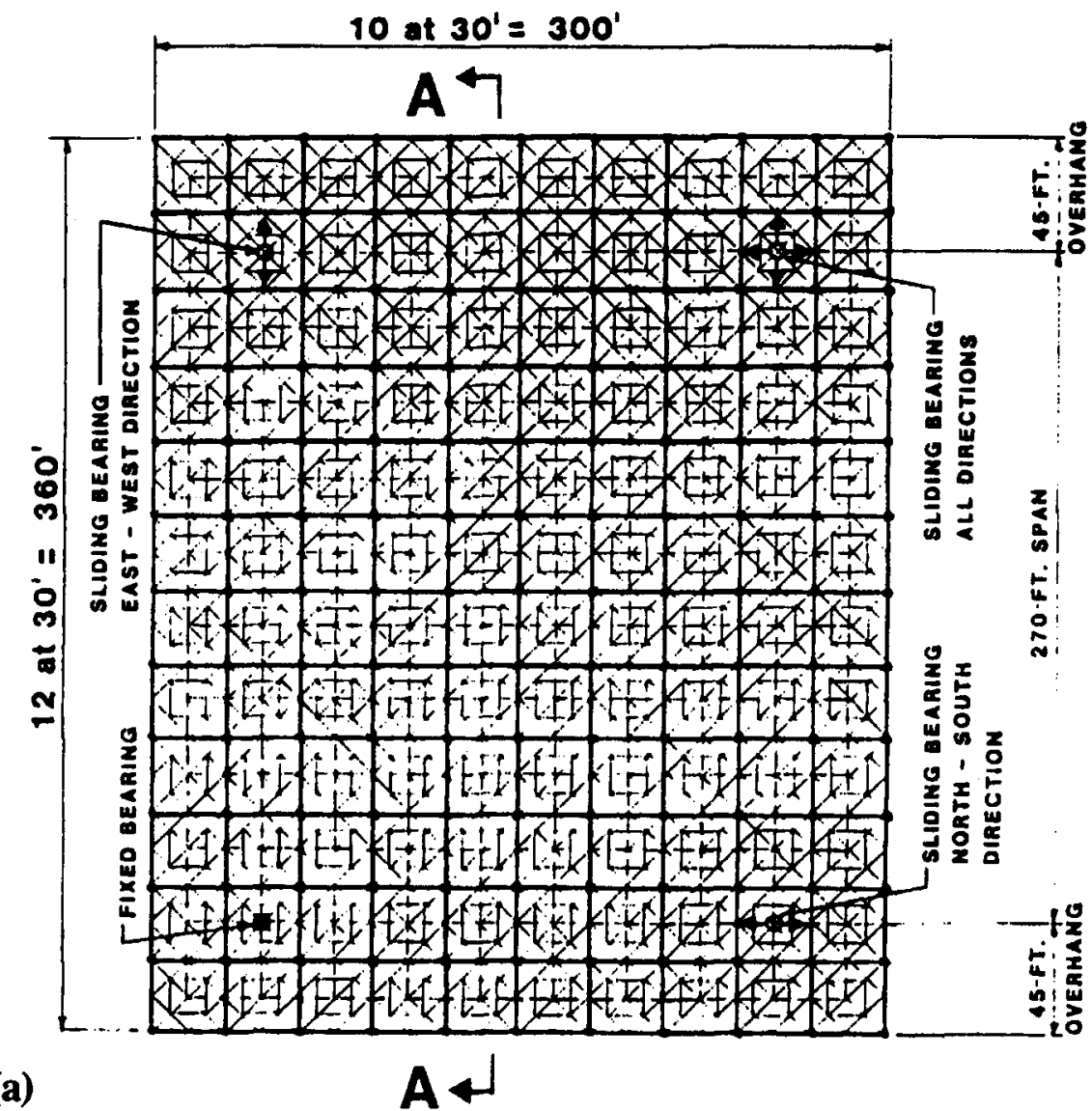

(a)

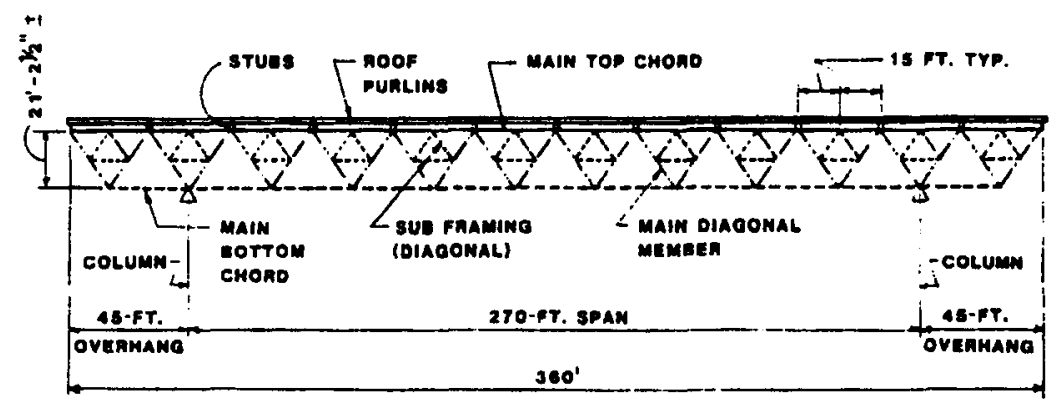

(b)

SECTION A - A

FIG. 10. Plan and Elevation of Roof Truss (Kaminetzky 1991) (Reprinted by Permission) 

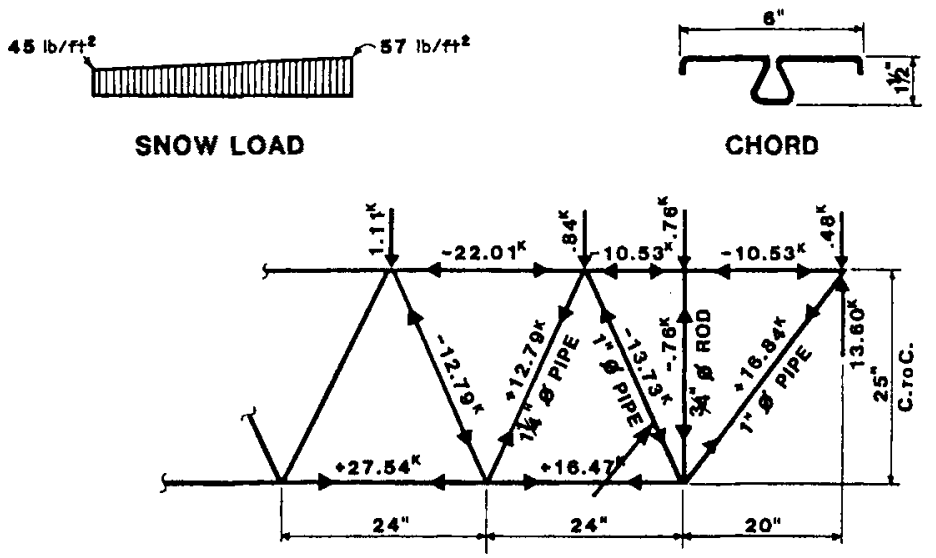

FIG. 11. Truss Member Forces (Kaminetzky 1991) (Reprinted by Permission)

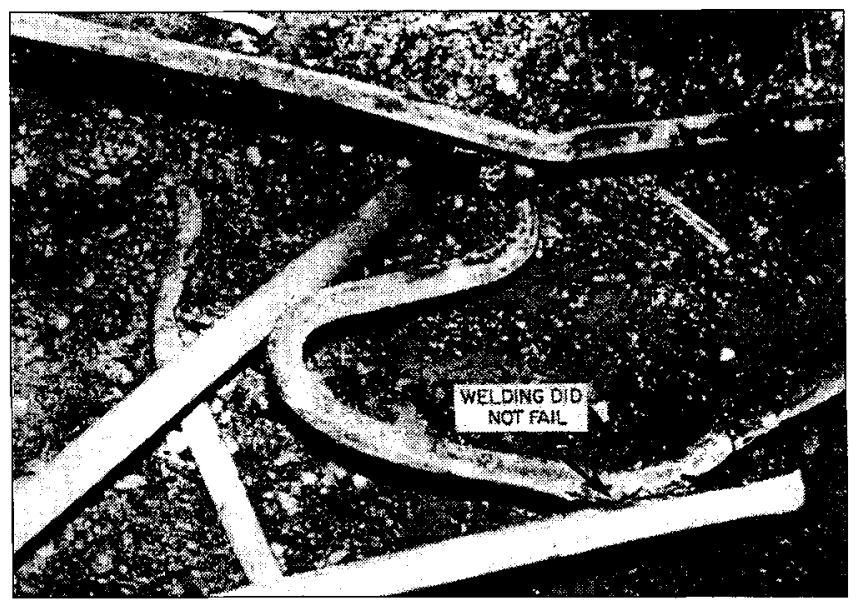

FIG. 12. Buckled Compression Diagonal (Kaminetzky 1991) (Reprinted by Permission)

Only six hours earlier, 5,000 people had been in the arena watching a basketball game. The arena roof was a $90-$ by 110-m space frame (Levy and Salvadori 1992; Kaminetzsky 1991; Feld and Carper 1997).

Technical Aspects and Calculations. During construction in 1972 and 1973, the inspection agency notified the engineers of excessive deflections (Levy and Salvadori 1992). The measured deflection of the root was twice that predicted by computer analysis. On the day of the collapse, the sum of dead and live loads was less than the design load. Plan and elevation views of the roof truss are shown in Fig. 10

The large deformations were a warning that the structure was not behaving as the computer model had predicted and was on the verge of collapse (Levy and Salvadori 1992). Kaminetzky (1991) suggests that the deformations were "cries for help" from the structure.

This case study can be introduced early in a mechanics of materials course when member deformations are first taught, and then discussed again when elastic buckling is encountered. Numerous factors contributed to the collapse, among them that the main top chords had a much lower buckling capacity than assumed in the original design analysis. The unbraced length of some compression members was $9.14 \mathrm{~m}$ rather than the assumed $4.57 \mathrm{~m}$; thus, the capacity was reduced $75 \%$ by this factor alone. Other factors reduced member capacity even further (Feld and Carper 1997), and this case study could be revisited several times to bring out specific points about three- dimensional structural behavior and the dangers of over-reliance on two-dimensional models.

Ethical Considerations. What measures should be taken when observed structural deformations greatly exceed predicted deformations? Should a structure that will kill 5,000 people if it collapses be designed with greater care and a higher factor of safety (Kaminetzky 1991)?

\section{Elastic Buckling: Stepped Roof Structure, Elwood, Long Island, N.Y.}

Learning Point. Elastic buckling may occur with little warning. Stepped roofs may have substantially higher local snow loads than flat roofs.

Narrative. After a heavy snowstorm, a stepped roof collapsed. The $1.7-\mathrm{m}$ differential level between parts of the roof allowed for the buildup of drifting snow. A compression diagonal on a roof truss buckled (Kaminetzky 1991)

Technical Aspects and Calculations. The truss is shown in Fig. 11, along with calculated member forces. The buckled compression diagonal is shown in Fig. 12. The elastic buckling capacity of the 25.4-mm diameter steep pipe (unbraced length $0.705 \mathrm{~m}, E=200 \mathrm{GPa}$ ) can be calculated as $55.6 \mathrm{kN}$ for 3.175 $\mathrm{mm}$ thick pipes or $76.2 \mathrm{kN}$ for 6.35 -mm thick pipe. The force in the truss member at the time of the collapse was $61.0 \mathrm{kN}$. Even a solid steel pipe of this diameter would only have an elastic buckling capacity of $81.3 \mathrm{kN}$, which would leave a very small factor of safety under the applied load.

Ethical Considerations. Some types of loads, such as drifting snow live load, require more thought from the engineer than simply copying them out of the building code. Occasionally, code loadings are applied incorrectly.

\section{SOURCES}

Kaminetzky (1991), Levy and Salvadori (1992), Shepherd and Frost (1995), and Feld and Carper (1997) provide a large number and variety of case studies. Many others can be found in the ASCE Journal of the Performance of Constructed Facilities or ENR.

\section{SUMMARY AND CONCLUSION}

This paper has demonstrated that many topics in fundamental engineering mechanics courses can be introduced or emphasized using failure case studies. An additional benefit is that these case studies provide opportunities to discuss the values and ethics of the engineering profession. Perhaps most importantly, they provide a way to inspire and spark the interest of engineering students.

\section{APPENDIX. REFERENCES}

Beasley, K. J. (1987). "Masonry cladding stress failures." J. Perf. Constr. Fac, May 1987.

Drysdale, R G Hamid, A. A and Baker, L. R. (1994). Masonry structures: behavior and design. Prentice-Hall, Inc., Englewood Cliffs, N.J.

Feld, J., and Carper, K. (1997). Construction failure, 2nd Ed., John Wiley \& Sons, Inc., New York, N.Y.

Hibbeler, R. C. (1995). Engineering mechanics: dynamics, 7th Ed., Prentice-Hall, Inc., Englewood Cliffs, N.J.

Kaminetzky, D (1991). Design and construction failures: lessons from forensic investigations. McGraw-Hill Inc., New York, N.Y.

Levy, M., and Salvadori, M. (1992). Why buildings fall down: how structures fail. W. W. Norton, New York, N.Y.

Mattar, S. G., and Morstead, T. R. (1987). "Shrinkage in concrete masonry walls: a case study." J. Perf. Constr. Fac., ASCE, 1(2), 103 119.

Rendon-Herrero, O. (1993). "Including failure case studies in civil engineering courses." J. Perf. Constr. Fac., ASCE, 7(3), 181-185.

Rubin, R. A., and Banick, L. A. (1987). "The Hyatt Regency decision: one view." J. Perf: Constr. Fac., ASCE, 161-167.

Shepherd, R., and Frost, J. D. (1995). Fuilures in civil engineering: structural, foundation, and geonvironmental case studies. ASCE, New York, N.Y. 